\title{
Controlled Growth of Gold Nanoparticles on Covellite Copper- Sulfide Nanoplatelets for the Formation of Plate-Satellite Hybrid Structures
}

Thomas Tsangas ${ }^{\dagger}$, Charlotte Ruhmlieb ${ }^{\dagger,}$, , Sebastian Hentschel ${ }^{\dagger}$, Heshmat Noei ${ }^{\ddagger}$, Andreas Stierle ${ }^{\ddagger}$, Tobias Kipp ${ }^{\dagger}$, Alf Mews ${ }^{\dagger}$

†Institute of Physical Chemistry, University of Hamburg, 20146 Hamburg, Germany

*Deutsches Elektronen-Synchrotron (DESY), Center for X-ray and Nano Science (CXNS), 22607 Hamburg, Germany

${ }^{*}$ To whom correspondence should be addressed.

Email: charlotte.ruhmlieb@chemie.uni-hamburg.de; Phone: +49 40 42838-7523; Fax: +49 40 4273-14796.

\section{ADDITIONAL TABLES}

Table SI1. Added amounts of copper-sulfide NPLs dispersed in toluene (CuS), tetrachloroauric(III) acid trihydrate solution $\left(\mathrm{Au}^{3+}\right)$, oleylamine $(\mathrm{OAm})$, oxalic-acid solution $(\mathrm{OA})$, and the reaction times $(\mathrm{t})$ used for the synthesis of CuS@Au hybrid structures.

\begin{tabular}{cccccc}
\hline Sample & CuS NPLS & $\mathbf{A u}^{3+}$ & OAm & OA & t \\
& $\mathbf{( 4 . 0 0 ~ m M )}$ & $(\mathbf{1 . 0 0} \mathbf{M})$ & & $(\mathbf{0 . 1 0 0} \mathbf{M})$ & \\
\hline CuS@Au-1 & $2.50 \mathrm{~mL}$ & $1.25 \mu \mathrm{L}$ & $50.0 \mu \mathrm{L}$ & $500 \mu \mathrm{L}$ & $5 \mathrm{~min}$ \\
CuS@Au-2 & $2.50 \mathrm{~mL}$ & $2.50 \mu \mathrm{L}$ & $50.0 \mu \mathrm{L}$ & $500 \mu \mathrm{L}$ & $5 \mathrm{~min}$ \\
CuS@Au-3 & $2.50 \mathrm{~mL}$ & $5.00 \mu \mathrm{L}$ & $50.0 \mu \mathrm{L}$ & $500 \mu \mathrm{L}$ & $5 \mathrm{~min}$ \\
CuS@Au-4 & $2.50 \mathrm{~mL}$ & $10.0 \mu \mathrm{L}$ & $50.0 \mu \mathrm{L}$ & $500 \mu \mathrm{L}$ & $5 \mathrm{~min}$ \\
CuS@Au-5 & $2.50 \mathrm{~mL}$ & $20.0 \mu \mathrm{L}$ & $50.0 \mu \mathrm{L}$ & $500 \mu \mathrm{L}$ & $5 \mathrm{~min}$ \\
\hline
\end{tabular}

Table SI2. Scanning parameters for the measurements of nitrogen and carbon dioxide from Figure SI16.

\begin{tabular}{ccccccc}
\hline Substance & $\begin{array}{c}\text { RS } \\
\text { value }\end{array}$ & Detector & $\begin{array}{c}\text { Emission } \\
\text { current }\end{array}$ & $\begin{array}{c}\text { Electron } \\
\text { energy }\end{array}$ & $\begin{array}{c}\text { Dwell } \\
\text { time }\end{array}$ & $\begin{array}{c}\text { Settle } \\
\text { time }\end{array}$ \\
\hline Nitrogen & 1 & Faraday & $200 \mu \mathrm{A}$ & $70 \mathrm{eV}$ & $150 \mathrm{~ms}$ & $250 \mathrm{~ms}$ \\
Carbon dioxide & 1 & SEM & $200 \mu \mathrm{A}$ & $70 \mathrm{eV}$ & $2750 \mathrm{~ms}$ & $400 \mathrm{~ms}$ \\
& & $(850 \mathrm{~V}$ & & & \\
& multiplier & & & \\
& voltage $)$ & & & \\
& & & & & \\
& & & & & \\
\end{tabular}


Table SI3. Corresponding average diameter of gold nanoparticles and average number of particles per CuS NPL from Figure SI5.

\begin{tabular}{ccc}
\hline Sample & $\begin{array}{c}\text { Average diameter of the Au } \\
\text { nanoparticles }\end{array}$ & $\begin{array}{c}\text { Average number of Au nanoparticles } \\
\text { per CuS NPL }\end{array}$ \\
\hline CuS@Au-1 & $4.2 \pm 2.8 \mathrm{~nm}$ & 0.9 \\
$\mathbf{C u S @ A u - 2}$ & $4.6 \pm 2.4 \mathrm{~nm}$ & 3.1 \\
$\mathbf{C u S @ A u - 3}$ & $5.0 \pm 2.2 \mathrm{~nm}$ & 6.3 \\
$\mathbf{C u S @ A u - 4}$ & $5.5 \pm 1.9 \mathrm{~nm}$ & 13.4 \\
$\mathbf{C u S @ A u - 5}$ & $5.8 \pm 2.0 \mathrm{~nm}$ & 26.3 \\
\hline
\end{tabular}

Table SI4. Calculation of the amount of copper and gold before and after the reaction of the different as-synthesized CuS@Au hybrid structures, based on ICP analysis.

\begin{tabular}{ccccc}
\hline Sample & $\begin{array}{c}\text { Cu amount } \\
\text { before reaction }\end{array}$ & $\begin{array}{c}\text { Cu amount } \\
\text { after reaction }\end{array}$ & $\begin{array}{c}\text { Au amount } \\
\text { before reaction }\end{array}$ & $\begin{array}{c}\text { Au amount } \\
\text { after reaction }\end{array}$ \\
\hline CuS@Au-1 & $10.0 \mu \mathrm{mol}$ & $9.87 \mu \mathrm{mol}$ & $1.25 \mu \mathrm{mol}$ & $1.04 \mu \mathrm{mol}$ \\
CuS@Au-2 & $10.0 \mu \mathrm{mol}$ & $9.86 \mu \mathrm{mol}$ & $2.5 \mu \mathrm{mol}$ & $1.24 \mu \mathrm{mol}$ \\
CuS@Au-3 & $10.0 \mu \mathrm{mol}$ & $9.88 \mu \mathrm{mol}$ & $5.0 \mu \mathrm{mol}$ & $3.42 \mu \mathrm{mol}$ \\
CuS@Au-4 & $10.0 \mu \mathrm{mol}$ & $9.94 \mu \mathrm{mol}$ & $10.0 \mu \mathrm{mol}$ & $9.70 \mu \mathrm{mol}$ \\
CuS@Au-5 & $10.0 \mu \mathrm{mol}$ & $9.87 \mu \mathrm{mol}$ & $20.0 \mu \mathrm{mol}$ & $19.17 \mu \mathrm{mol}$ \\
\hline
\end{tabular}

Table SI5. Corresponding average diameter of CuS NPLs and gold nanoparticles, average thickness of CuS NPLs and average number of gold nanoparticles per CuS NPL from Figure SI7 and SI8.

\begin{tabular}{ccccc}
\hline Sample & $\begin{array}{c}\text { Average diameter } \\
\text { of the CuS NPLs }\end{array}$ & $\begin{array}{c}\text { Average } \\
\text { thickness of the } \\
\text { CuS NPLs }\end{array}$ & $\begin{array}{c}\text { Average diameter } \\
\text { of the Au } \\
\text { nanoparticles }\end{array}$ & $\begin{array}{c}\text { Average number } \\
\text { of Au } \\
\text { nanoparticles per } \\
\text { CuS NPL }\end{array}$ \\
\hline $\mathbf{0} \mathbf{~} \mathbf{m}$ & $70.8 \pm 7.6 \mathrm{~nm}$ & $4.4 \pm 0.7 \mathrm{~nm}$ & - & - \\
$\mathbf{0 . 5} \mathbf{~ m i n}$ & $69.0 \pm 7.6 \mathrm{~nm}$ & $4.6 \pm 0.6 \mathrm{~nm}$ & $5.0 \pm 2.1 \mathrm{~nm}$ & 25.8 \\
$\mathbf{5} \mathbf{~} \mathbf{m i n}$ & $70.0 \pm 8.6 \mathrm{~nm}$ & $4.5 \pm 0.6 \mathrm{~nm}$ & $5.6 \pm 2.0 \mathrm{~nm}$ & 26.3 \\
\hline
\end{tabular}

Table SI6. Corresponding average diameter of gold nanoparticles and average number of particles per CuS NPL from Figure SI5 and SI11.

\begin{tabular}{ccc}
\hline Temperature & $\begin{array}{c}\text { Average diameter of the } \\
\text { Au nanoparticles }\end{array}$ & $\begin{array}{c}\text { Average number of Au nanoparticles } \\
\text { per } \mathbf{C u S ~ N P L}\end{array}$ \\
\hline $\mathbf{2 4}^{\circ} \mathbf{C}$ & $5.8 \pm 2.0 \mathrm{~nm}$ & 26.3 \\
$\mathbf{6 0}^{\circ} \mathbf{C}$ & $5.5 \pm 2.3 \mathrm{~nm}$ & 27.1 \\
\hline
\end{tabular}

Table SI7. Corresponding average diameter of gold nanoparticles and average number of particles per CuS NPL from Figure SI5 and SI17.

\begin{tabular}{ccc}
\hline $\mathbf{O A}$ & $\begin{array}{c}\text { Average diameter of the } \\
\text { Au nanoparticles }\end{array}$ & $\begin{array}{c}\text { Average number of Au nanoparticles } \\
\text { per CuS NPL }\end{array}$ \\
\hline $\mathbf{0 . 1 0 0} \mathbf{~ M )}$ & $5.8 \pm 2.0 \mathrm{~nm}$ & 26.3 \\
$\mathbf{5 0 0} \boldsymbol{\mu L}$ & $5.2 \pm 2.9 \mathrm{~nm}$ & 26.4 \\
$\mathbf{3 0 0} \boldsymbol{\mu L}$ & $4.5 \pm 2.0 \mathrm{~nm}$ & 27.2 \\
\hline $\mathbf{1 0 0} \boldsymbol{\mu L}$ & & \\
\hline
\end{tabular}


Table SI8. Binding Energy $(\mathrm{eV})$ of $\mathrm{Au}, \mathrm{Cu}$, and $\mathrm{S}$ obtained from high-resolution XP spectra of CuS NPLs (0 min) and CuS@Au hybrid structures (0.5 min and 5 min) from Figure SI19.

\begin{tabular}{|c|c|c|c|c|c|}
\hline 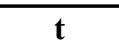 & $\operatorname{Au} \mathbf{4 f _ { 5 / 2 }}$ & $\operatorname{Au} \mathbf{4} \mathbf{f}_{7 / 2}$ & $\mathrm{Cu} 2 \mathrm{p}_{1 / 2}$ & $\mathrm{Cu} 2 \mathrm{p}_{3 / 2}$ & S 2p \\
\hline $0 \mathrm{~min}$ & - & - & $951.6 \mathrm{eV}$ & $931.7 \mathrm{eV}$ & $161.7 \mathrm{eV}$ \\
\hline $0.5 \mathrm{~min}$ & $87.3 \mathrm{eV}$ & $83.7 \mathrm{eV}$ & $951.7 \mathrm{eV}$ & $931.8 \mathrm{eV}$ & $161.9 \mathrm{eV}$ \\
\hline $5 \mathrm{~min}$ & $87.3 \mathrm{eV}$ & $83.7 \mathrm{eV}$ & $952.0 \mathrm{eV}$ & $932.1 \mathrm{eV}$ & $161.9 \mathrm{eV}$ \\
\hline
\end{tabular}

Table SI9. XP peak assignment and correspond from Figure 7. The areas of the different components are analyzed to calculate the relative ratio between the disulfide bridges and sulfide of the $\mathrm{CuS}$.

\begin{tabular}{|c|c|c|c|c|}
\hline $\mathbf{t}$ & $\left(S_{2}^{-}\right) 2 p_{1 / 2}$ & $\left(S_{2}^{-}\right) 2 p_{3 / 2}$ & $\left(S^{2-}\right) 2 p_{1 / 2}$ & $\left(S^{2-}\right) 2 p_{3 / 2}$ \\
\hline 0 min & 0.17 & 0.34 & 0.50 & 1 \\
\hline $0.5 \mathrm{~min}$ & 0.10 & 0.20 & 0.50 & 1 \\
\hline $5 \mathrm{~min}$ & 0.09 & 0.18 & 0.50 & 1 \\
\hline & \multicolumn{2}{|c|}{ Disulfides } & \multicolumn{2}{|c|}{ Sulfides } \\
\hline $0 \mathrm{~min}$ & \multicolumn{2}{|c|}{0.34} & \multicolumn{2}{|c|}{1} \\
\hline $0.5 \mathrm{~min}$ & \multicolumn{2}{|c|}{0.20} & \multicolumn{2}{|c|}{1} \\
\hline $5 \mathrm{~min}$ & \multicolumn{2}{|c|}{0.18} & \multicolumn{2}{|c|}{1} \\
\hline
\end{tabular}

\section{ADDITIONAL FIGURES}

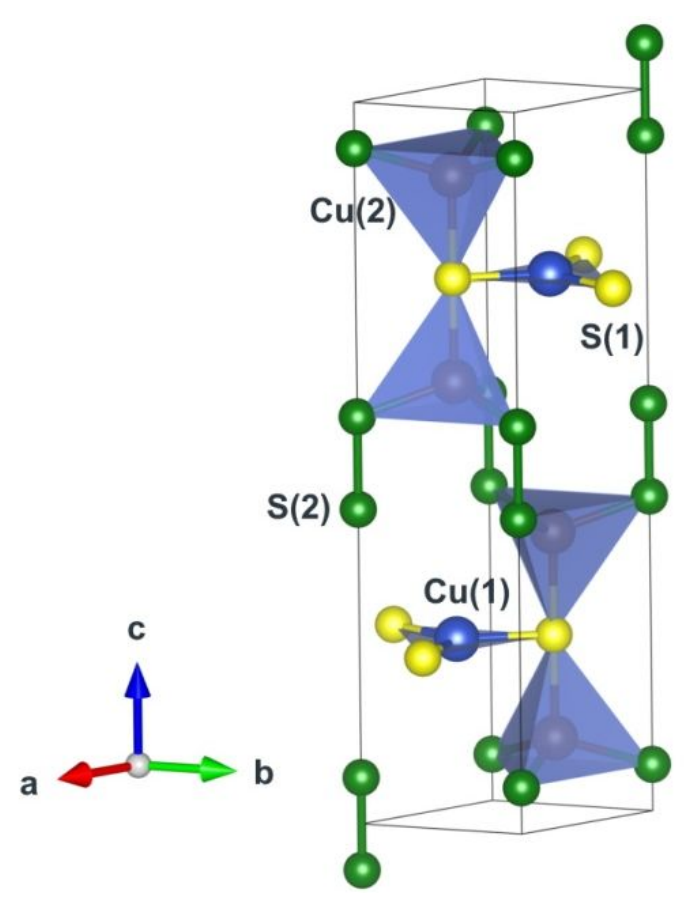

Figure SI1. 3D polyhedral hexagonal unit cell of covellite (CuS). The unit cell contains twelve atoms, six each of copper and sulfur, in which two $\mathrm{Cu}(1)$ atoms (blue) have triangular planar coordination with three $\mathrm{S}(1)$ atoms (yellow). Each $\mathrm{Cu}(2)$ atom (brown) has a tetrahedral coordination with one $\mathrm{S}(1)$ and three $\mathrm{S}(2)$ (green) atoms. From the model, it appears that the crystal structure consists of alternating $\mathrm{CuS}_{4}-\mathrm{CuS}_{3}-\mathrm{CuS}_{4}$ layers along the c-axis. The $\mathrm{CuS}_{4}-\mathrm{CuS}_{3}-\mathrm{CuS}_{4}$ planes are here connected by S-S bonding. 

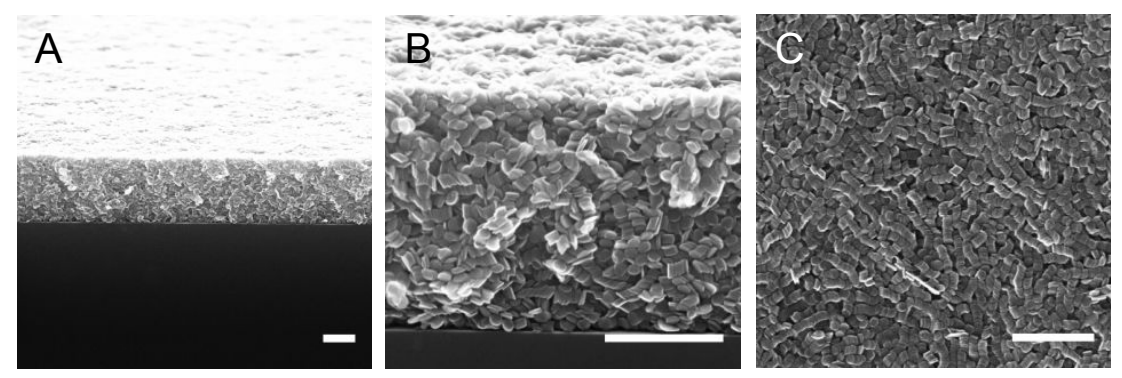

Figure SI2. SEM (A and B) side view and (C) top view images of a CuS-nanoplatelet film prepared by the drop-casting method on a silicon wafer (scale bars: $500 \mathrm{~nm}$ ).
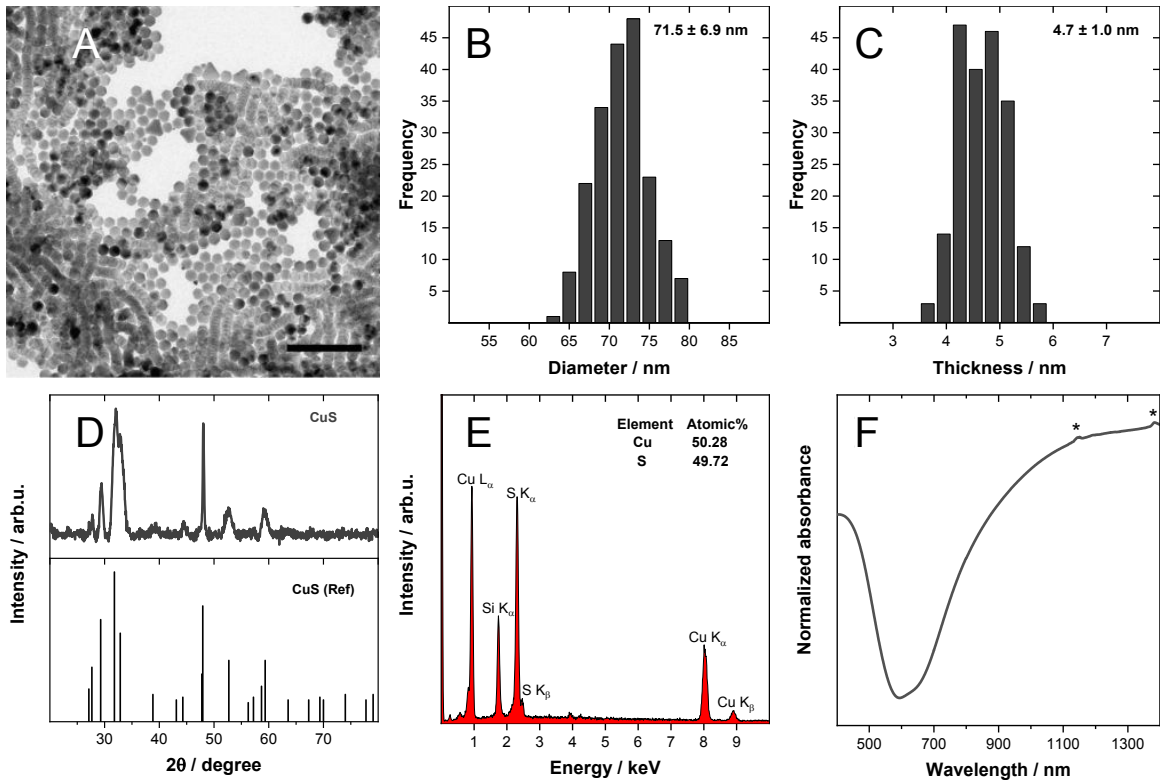

Figure SI3. (A) TEM image (scale bar: $500 \mathrm{~nm}$ ) with the corresponding size distribution of the (B) diameter and (C) thickness, (D) PXRD pattern, (E) EDS spectrum, and (F) UV/Vis/NIR spectrum of CuS NPLs. A standard XRD pattern of covellite copper sulfide (ICDD pattern no. 06-0464) was used as reference. The Si-signal in the EDS measurement originates from the silicon substrate used for this measurement. * The peaks at $1145 \mathrm{~nm}$ and $1382 \mathrm{~nm}$ can be attributed to the solvent's absorbance. 

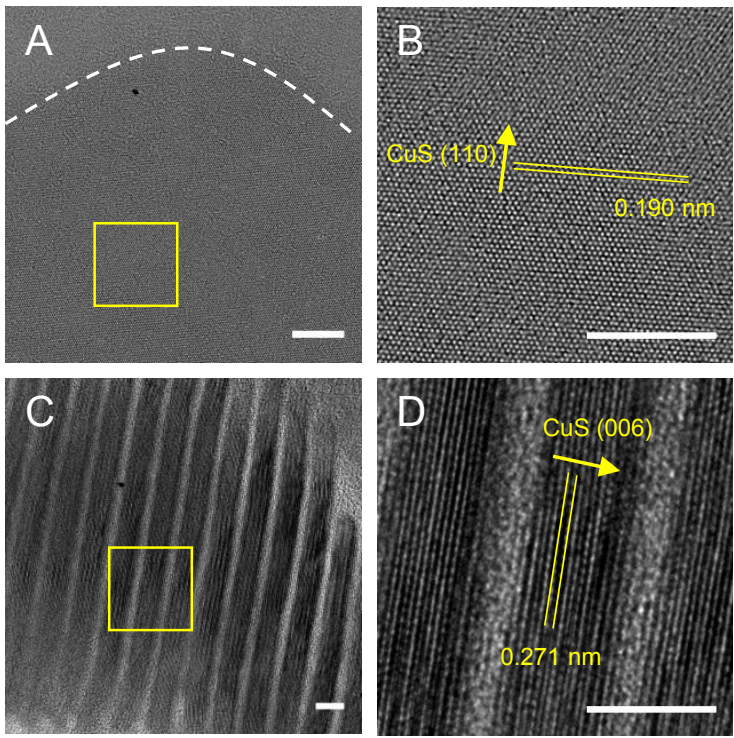

Figure SI4. HRTEM images of a single CuS NPLs (A) flat on the TEM grid and (B) of several CuS NPLs arranged face-to-face. HRTEM images of the selected regions enclosed by the square in (B) panel A and (D) panel C (scale bars: $5 \mathrm{~nm})$.
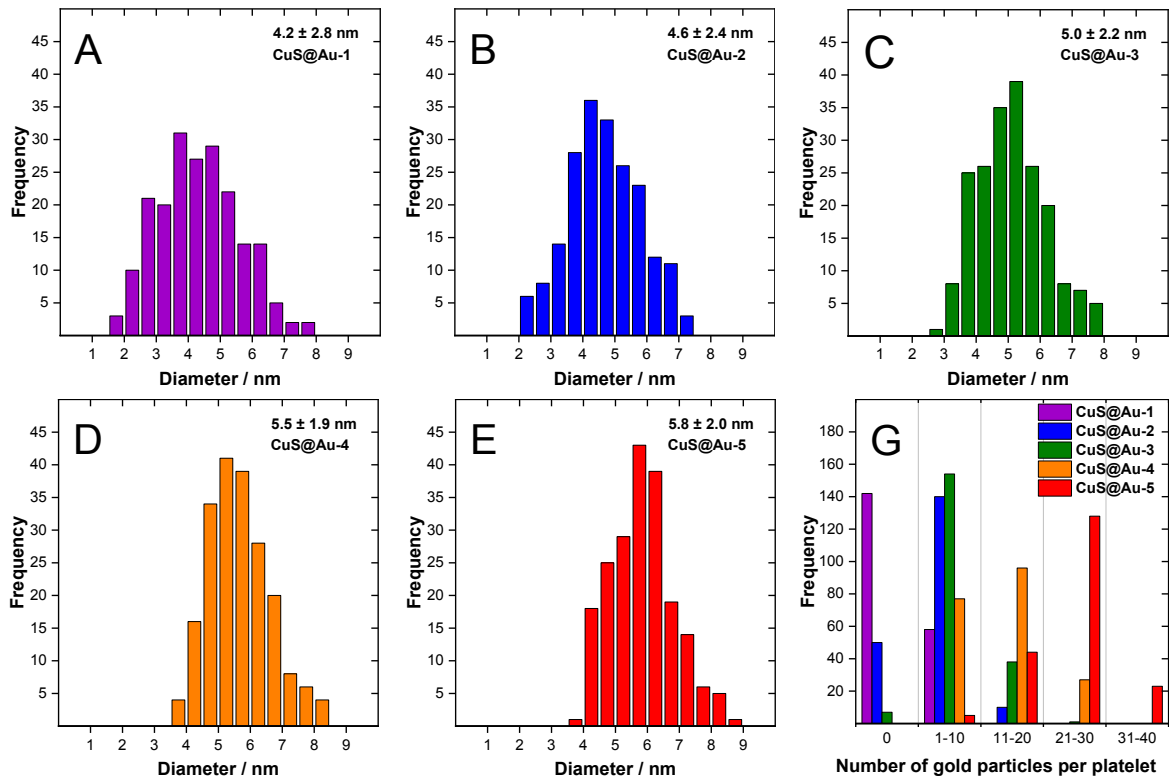

Figure SI5. (A-E) Size distributions of gold nanoparticle diameter and (F) number distribution of particles per CuS NPL. The CuS@Au hybrid structures were prepared with increasing amounts of gold from CuS@Au-1 to CuS@Au-5. For the size distributions, over 200 particles were counted in TEM images for each sample. 


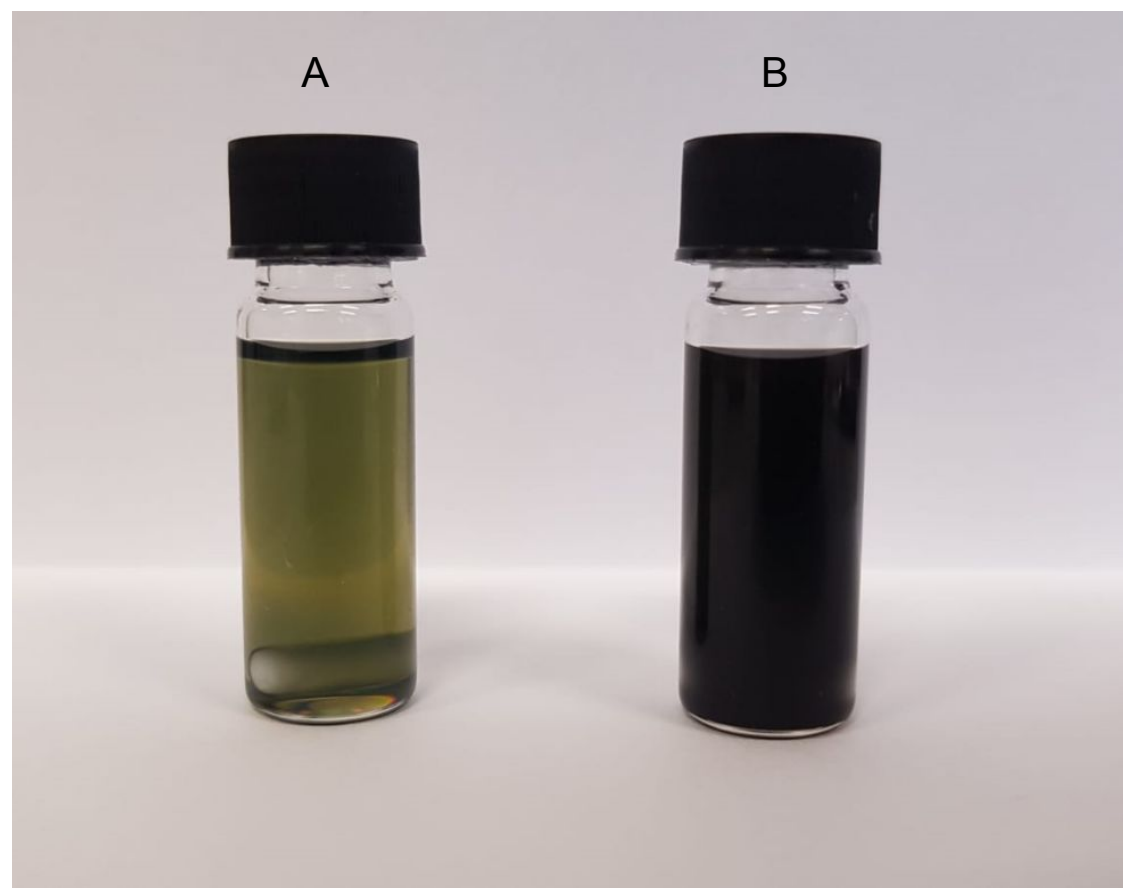

Figure SI6. Photo of a sample of colloidal (A) CuS NPLs and (B) CuS@Au hybrid structures, each stored in toluene.
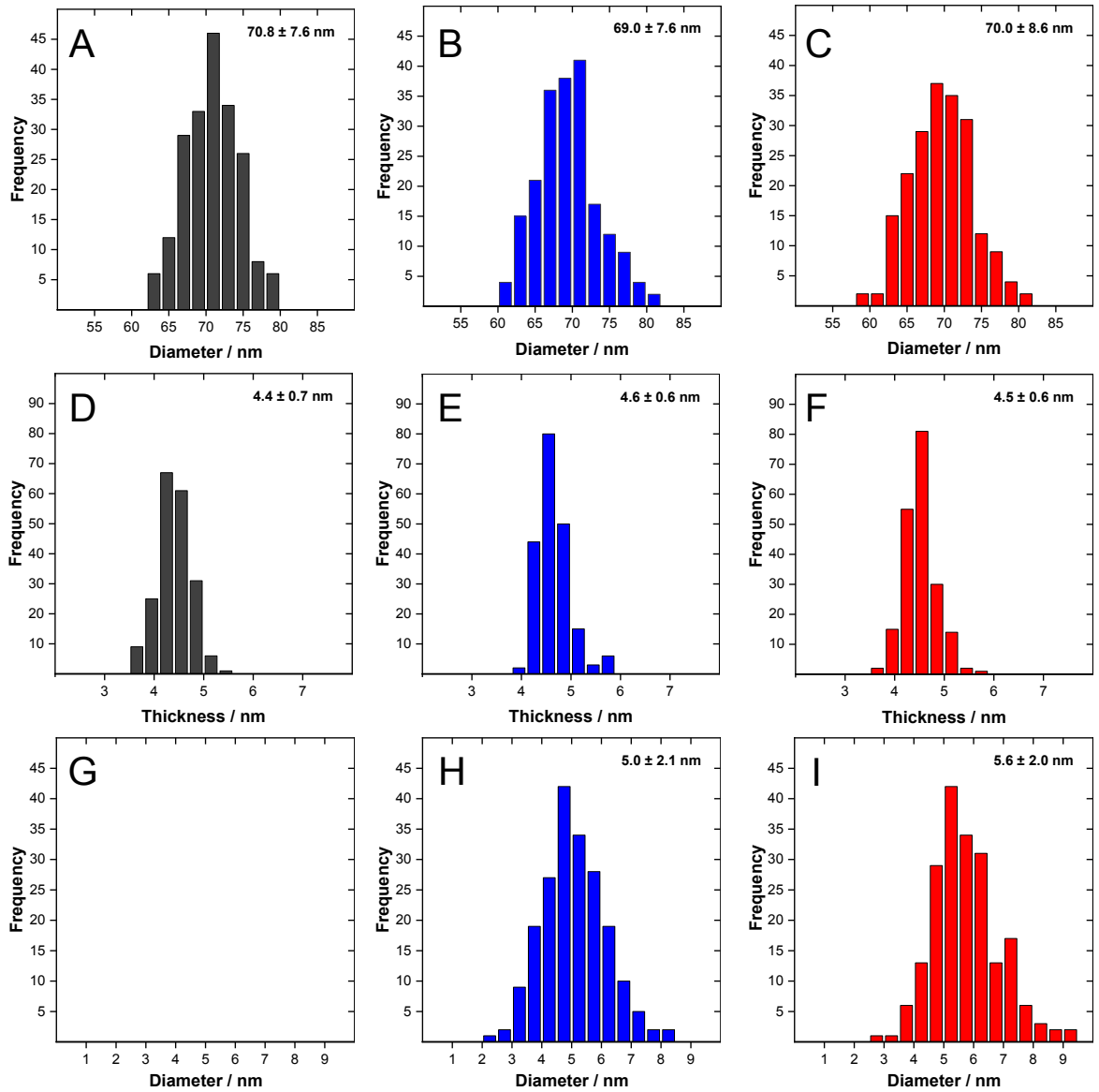

Figure SI7. Size distributions of the (A-C) CuS NPL diameter, (D-F) thickness, and (G-I) gold nanoparticle diameter of (black)CuS and CuS@Au hybrid structures synthesis with a reaction time of (blue) $0.5 \mathrm{~min}$ and (red) $5 \mathrm{~min}$. The size distributions were obtained from more than 200 particles in TEM images. 


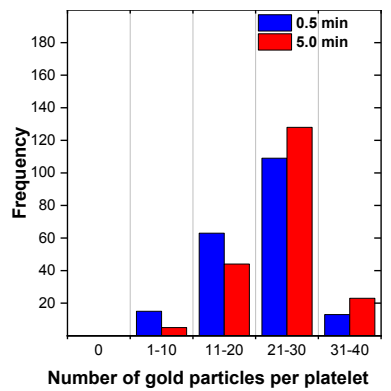

Figure SI8. Number distribution of gold nanoparticles per CuS NPL after (blue) $0.5 \mathrm{~min}$ and (red) 5 min reaction time. For each sample, more than 200 particles were counted in the TEM images.
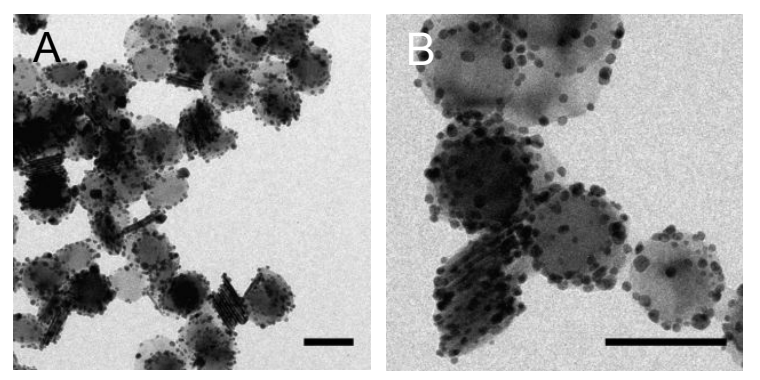

Figure SI9. (A) Low magnification and (B) close-up TEM images of CuS@Au hybrid structures produced under illumination with an artificial sun (power density: $4 \mathrm{~mW} \cdot \mathrm{cm}^{-2}$ ) (scale bars: $100 \mathrm{~nm}$ ).
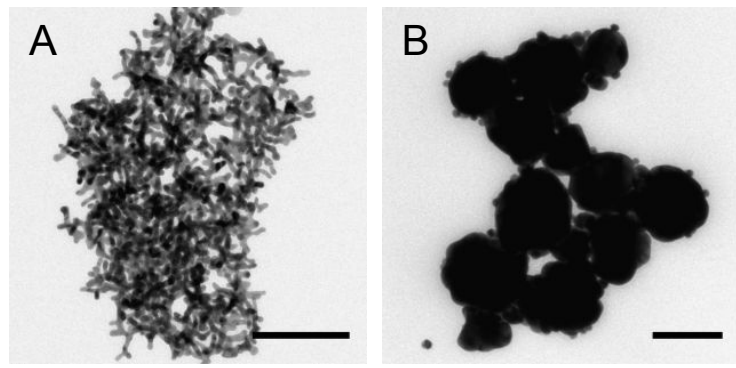

Figure SI10. TEM images of gold nanostructures prepared by adding $20 \mu \mathrm{L} \mathrm{Au}{ }^{3+}$ solution $(1.0 \mathrm{M})$ and $500 \mu \mathrm{L}$ oxalicacid solution $(0.1 \mathrm{M})$ to $2.5 \mathrm{~mL}$ toluene under nitrogen atmosphere and light exclusion for $5 \mathrm{~min}(\mathrm{~A})$ with and (B) without additional use of $50 \mu \mathrm{L}$ oleylamine (scale bars: $100 \mathrm{~nm}$ ).
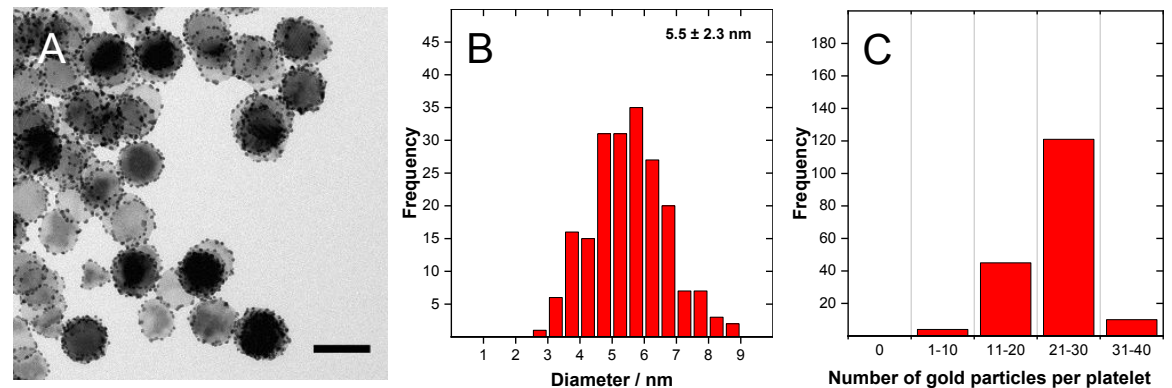

Figure SI11. (A) TEM image of CuS@Au hybrid structures synthesized at $60{ }^{\circ} \mathrm{C}$ (scale bars: $100 \mathrm{~nm}$ ) with (B) the corresponding size distribution of the gold nanoparticle diameter and (C) number distribution of particles per CuS NPL. More than 200 particles were counted for number distribution and size distribution. 
A
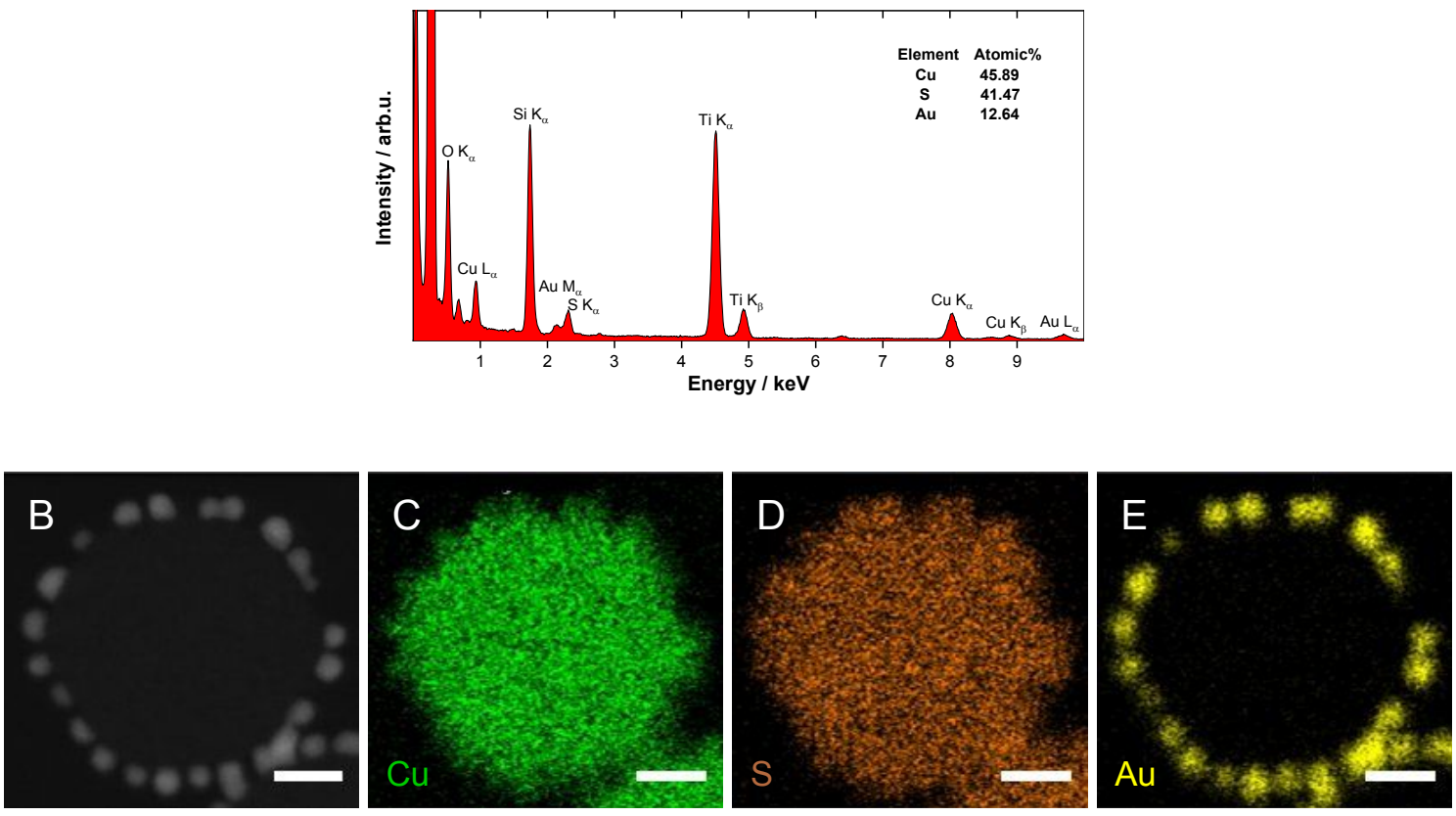

Figure SI12. (A) EDS spectrum, (B) HAADF-STEM image and the corresponding EDS mappings of (C) copper, (D) sulfur and (E) gold of a single CuS@Au hybrid structure (scale bars: $5 \mathrm{~nm}$ ). The Ti signals in the EDS spectrum originate from the titanium TEM grid.
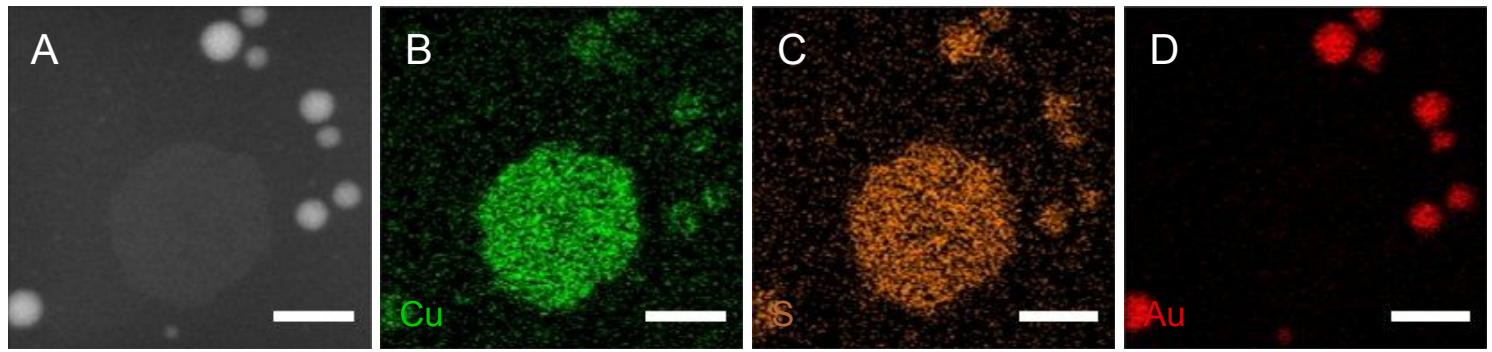

Figure SI13. (A) HAADF-STEM image and the corresponding EDS mappings of (B) copper, (C) sulfur, and (D) gold from a CuS NPL and gold nanoparticles. Both nanostructures were synthesized individually and then prepared on the same TEM grid (scale bars: $25 \mathrm{~nm}$ ). Due to the measurement procedure, copper and sulfur signals can be observed not only in the CuS NPL, but also where gold is present.
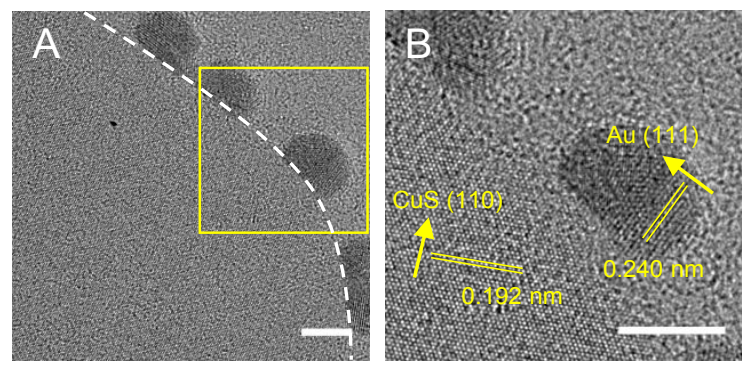

Figure SI14. (A) HRTEM image of a single CuS@Au hybrid structure flat on the TEM grid and (B) HRTEM close-up image of the selected region enclosed by the square (scale bars: $5 \mathrm{~nm}$ ). 

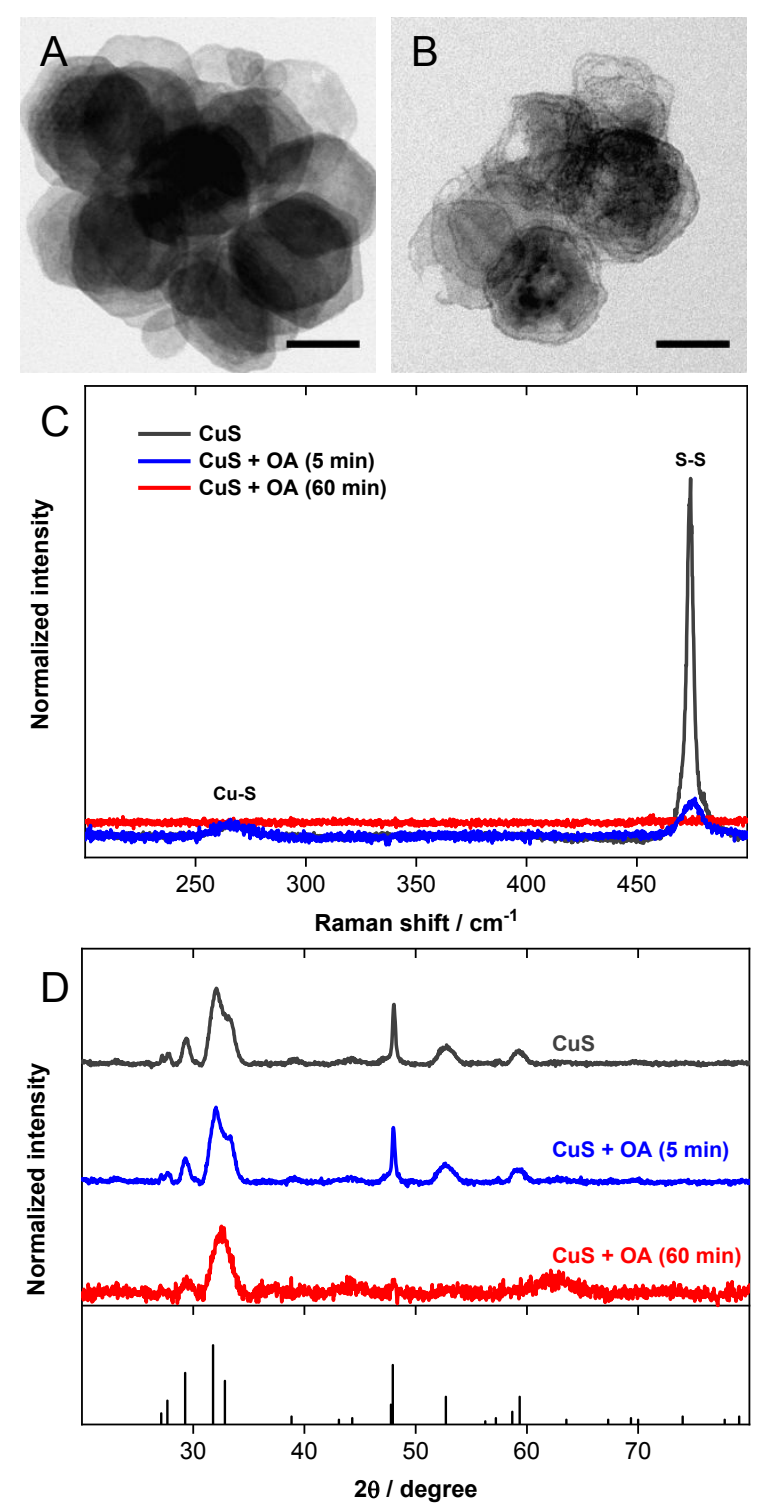

Figure SI15. (A-B) TEM images of CuS NPLs mixed with $500 \mu \mathrm{L}$ of an oxalic-acid solution (0.1 M) for (A) 5 min and (B) $60 \mathrm{~min}$ (scale bars: $50 \mathrm{~nm}$ ) and the corresponding (C) Raman spectra and (D) PXRD patterns. All Raman spectra were normalized to 1 at $267.1 \mathrm{~cm}^{-1}$ for clarity. The normalized PXRD patterns are offset for better visibility. A standard XRD pattern of covellite copper sulfide (ICDD pattern no. 06-0464) was used as reference.
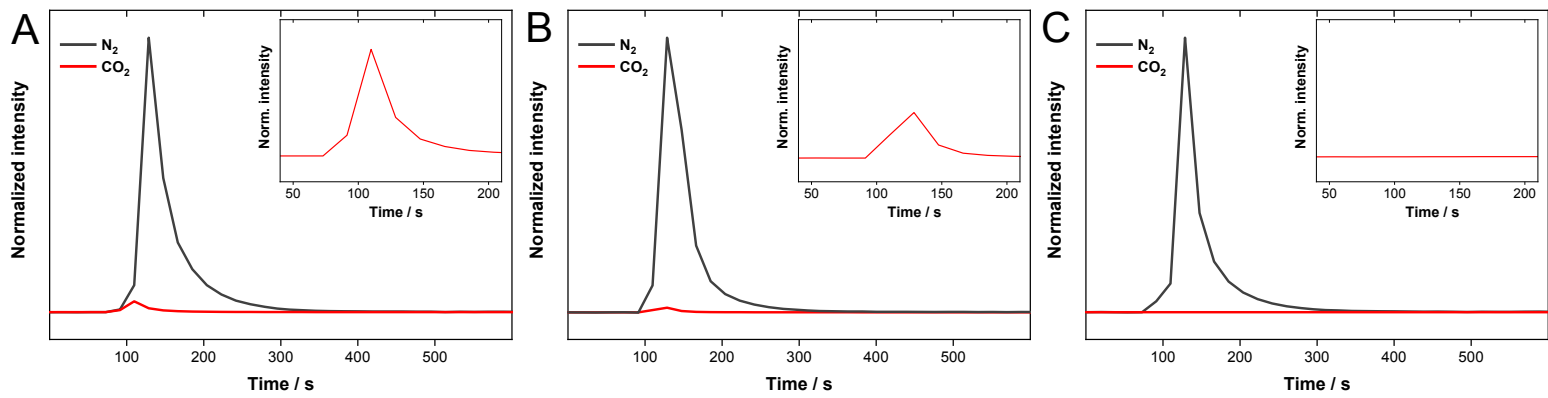

Figure SI16. Intensity of nitrogen and carbon dioxide measured over time in multiple ion detection mode. The gas atmosphere of an argon-fed (continuous flow) piping system is analyzed after injecting defined volumes of gas phase formed (A) during the standard growth procedure of CuS@Au hybrid structures (B) mixing CuS NPLs with $500 \mu \mathrm{L}$ of a oxalic-acid solution $(0.1 \mathrm{M})$. For comparison, the gas phase of the negative control $(\mathrm{C})(\mathrm{CuS}$ NPLs in $(5: 1(\mathrm{v} / \mathrm{v})$ toluene/methanol) was additionally measured. The time $\mathrm{t}=0 \mathrm{~s}$ represents the moment of the gas injection. All graphs were normalized to the corresponding highest intensity value for nitrogen. 


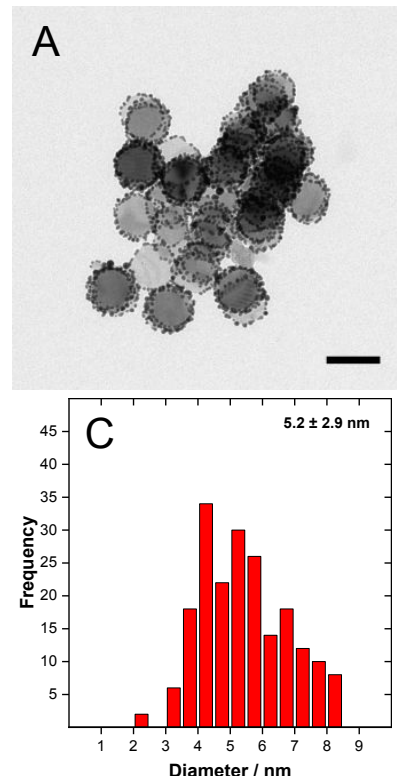

B
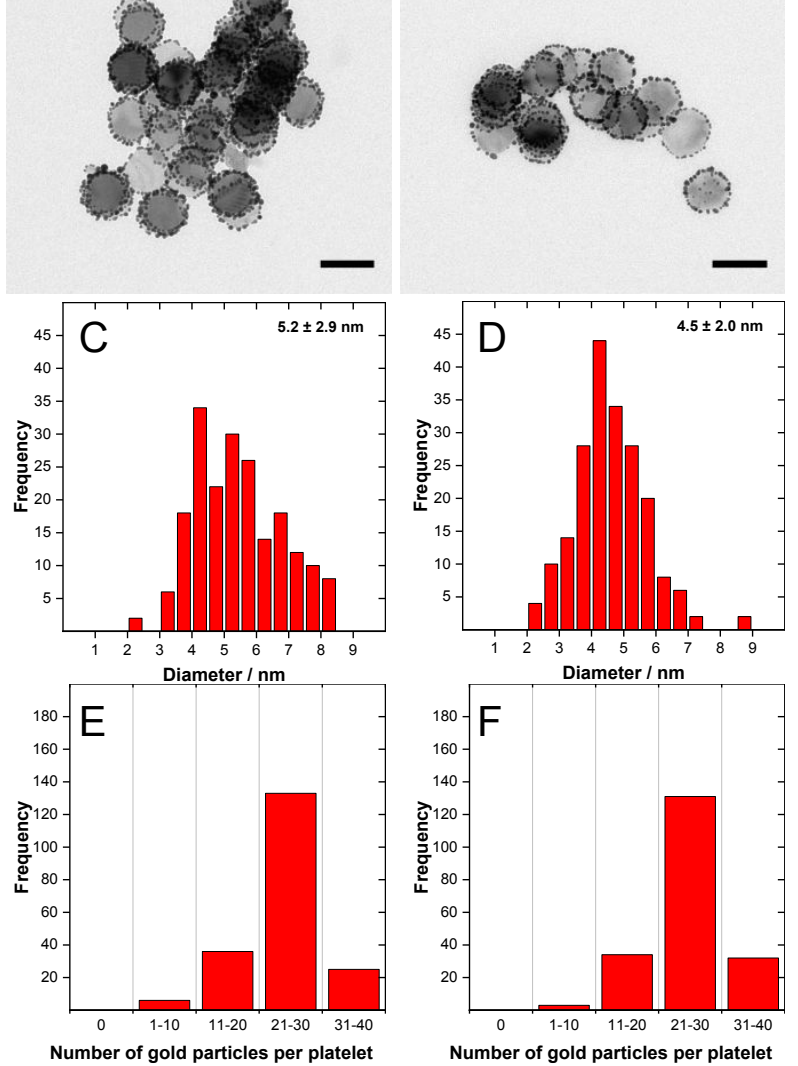

Figure SI17. TEM images of CuS@Au hybrid structures synthesized with (A) $300 \mu \mathrm{L}$ and (B) $100 \mu \mathrm{L}$ of an oxalic-acid solution $(0.1 \mathrm{M})$ (scale bars: $100 \mathrm{~nm}$ ) with the corresponding (C for A and D for B) size distribution of the gold nanoparticle diameter and (E for A and F for B) number distribution of particles per CuS NPL. More than 200 particles were counted for number distribution and size distribution. 

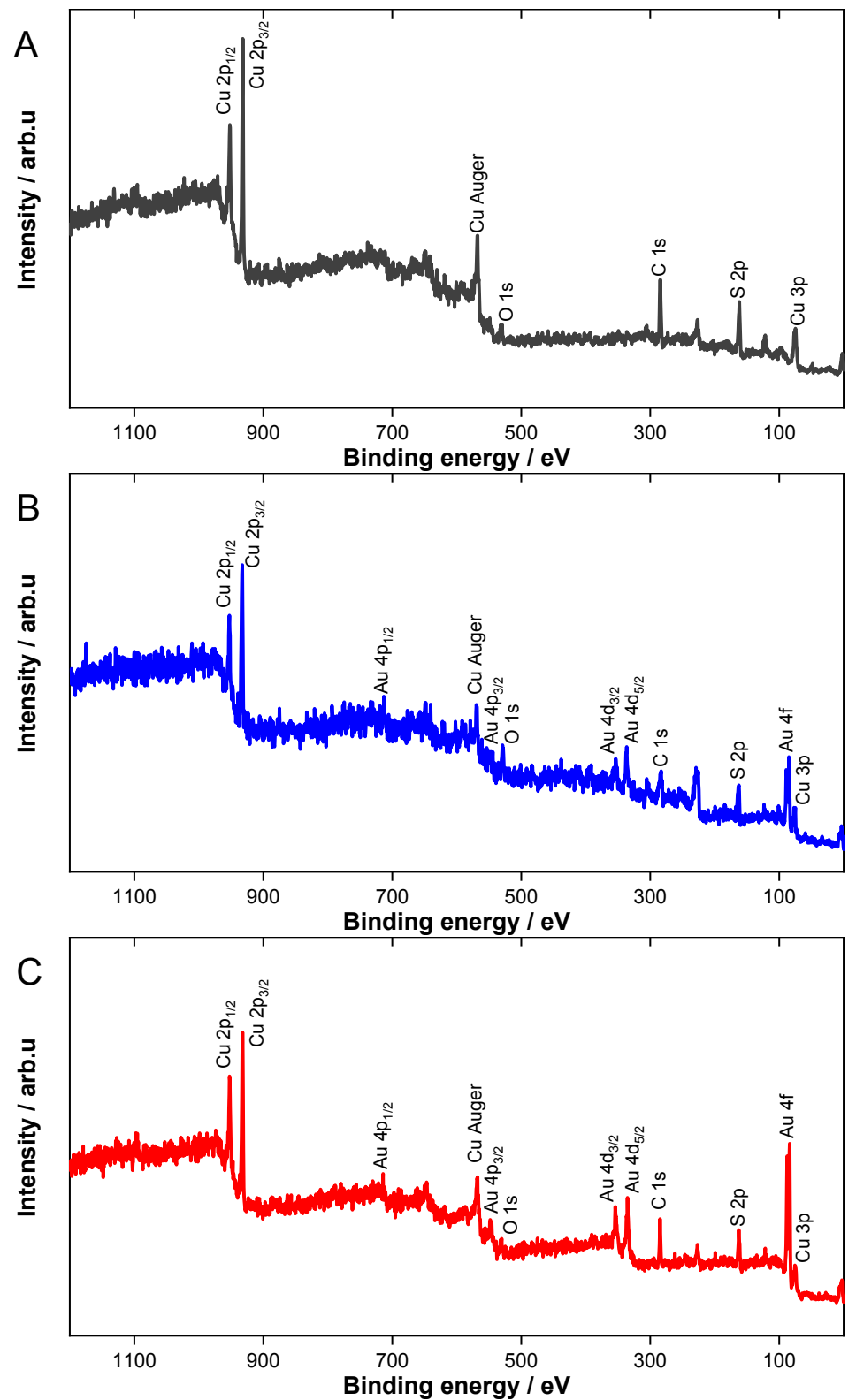

Figure SI18. Survey XP spectra of (A) CuS NPLs and CuS@Au hybrid structures synthesis with different reaction times of (B) $0.5 \mathrm{~min}$ and (C) $5 \mathrm{~min}$.
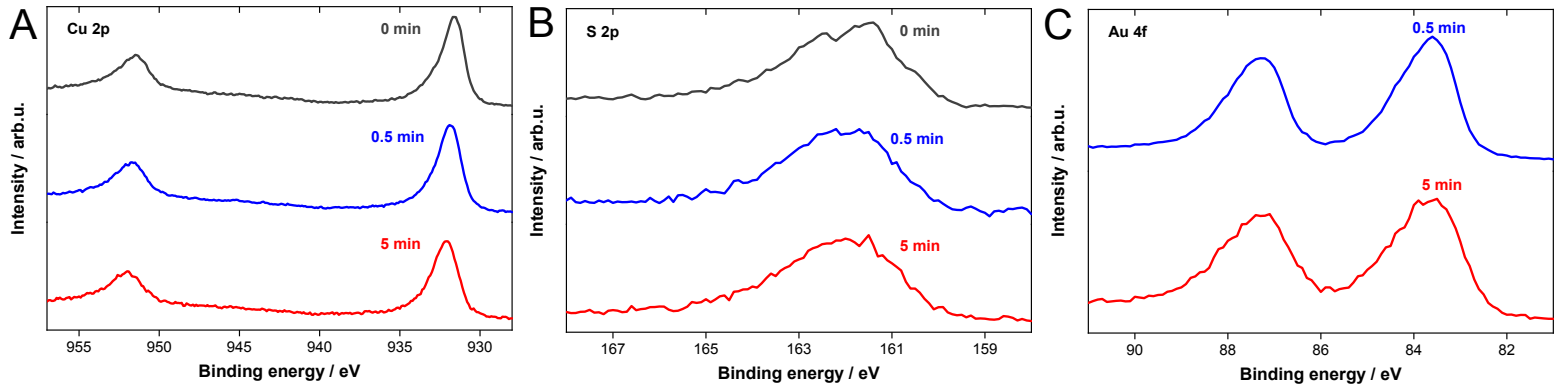

Figure SI19. High-resolution XP spectra of (A) Cu 2p, (B) S 2p, and (C) Au 4f in CuS NPLs and CuS@Au hybrid structures synthesized with a reaction time of $0.5 \mathrm{~min}$ and $5 \mathrm{~min}$. 

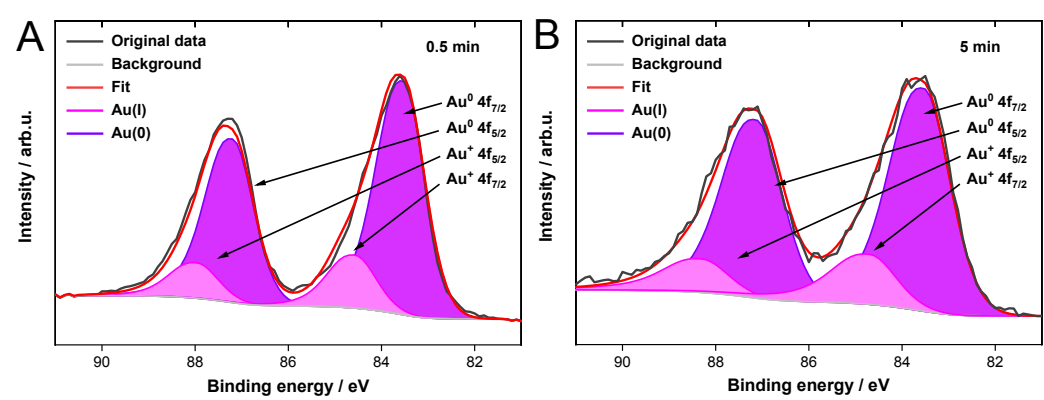

Figure SI20. High-resolution XP spectra of Au 4f in CuS@Au hybrid structures synthesis with a reaction time of (A) $0.5 \mathrm{~min}$ and (B) $5 \mathrm{~min}$. 